\title{
TAM e Azaléia: processos de transição em empresas familiares
}

\section{(TAM and Azaleia: transition’s processes in family businesses)}

\author{
Roberto Minadeo \\ rminadeo@yahoo.com \\ Professor do Programa de Mestrado em Administração do Centro Universitário Euro Americano - UNIEURO \\ Marlene Catarina de Oliveira Lopes Melo \\ lenemelo@unihorizontes.br \\ Diretora Geral e Coordenadora do Mestrado em Administração da Faculdade Novos Horizontes \\ Clara Márcia Ribeiro \\ clara.mkt@gmail.com \\ Mestranda da Universidade Federal do Paraná
}

Editor Científico Responsável: Prof ${ }^{a}$. Dra. Denize Grzybovski

Professora da Faculdade de Ciências Econômicas, Administrativas e Contábeis da Universidade de Passo Fundo

Recebido em: 20/02/08

Aprovado em: 23/04/09

\begin{abstract}
Resumo
Neste artigo focalizam-se os processos sucessórios de empresas familiares - cujo papel é relevante, havendo uma breve apresentação do tema. Os objetivos foram analisar, contextualizar e comparar os processos em duas empresas, a fim de discutir suas consequências para a continuidade dos negócios. O estudo é qualitativo, exploratório e descritivo, baseado em pesquisa documental, mediante dados da imprensa de negócios e trabalhos acadêmicos. As informações foram analisadas pela descrição e comparação de suas trajetórias - com ênfase nos processos sucessórios, na análise das mudanças implantadas e dos resultados obtidos. Foram escolhidas a Azaléia e a TAM - marcadas pelo falecimento de seus fundadores, em uma época crítica em seus respectivos setores. Os processos apresentaram complexos problemas iniciais, porém, nos dois casos, houve resultados satisfatórios. Dado que as sucessões não foram familiares, deve-se falar mais propriamente em processos de transição.
\end{abstract}

Palavras-chave: Processo de sucessão. Empresas familiares. Estratégia empresarial.

\begin{abstract}
The article focuses on the succession processes in familiar companies - which role is important, having one brief presentation in the subject. The objectives had been: to analyze, and compare such processes in two companies, in order to argue its consequences for the continuity of the businesses. The study is qualitative, exploratory and descriptive, based in documentary research, by means of business-oriented data of the press and of academic works. The information had been analyzed by means of the description and comparison of its historical trajectories - with emphasis in the succession, and the analysis of the changes and the results. Azaléia and TAM - marked by the death of its founders had been chosen as objects of the article, because they were a critical time in its respective sectors. Both processes had been reached reasonable results. Since the succession was not familiar, properly they must be described as transition processes.
\end{abstract}

Key word: Succession process. Familiar companies. Business strategy. 


\section{INTRODUÇÃO}

As empresas familiares compõem uma parte importante da economia e da sociedade e, apesar de vistas normalmente como pequenos negócios, elas também incluem razoável número de grandes organizações. Estão adquirindo importância e representatividade em economias nacionais e mundiais (CHURCHILL; HATTEN, 1987; BORNHOLDT, 2005; NEUBAUER; LANK, 1999; STEIER; CHIRISMAN; CHUA, 2004). Costumam apresentar quatro estágios em sua gestão: a) jovem família empresária: período de início e de definição dos papéis dos elementos familiares envolvidos; b) entrada na empresa de novas gerações; c) trabalho conjunto: procuram-se administrar as complexas relações familiares; d) passagem do bastão, que trata da resolução do problema da sucessão familiar. Sobre a escolha do sucessor, este não deve tentar ser uma cópia do fundador e nem mostrar que tem ideias melhores sobre o negócio. Assim, introduz naturalmente o tema do processo de sucessão - que é visto como um componente estratégico no escopo dessas organizações, pois necessita de planejamento para a preparação do sucessor, de tal forma que sua entrada e gestão não resultem em consequências negativas para a empresa (COSTA, 2006; CAPELÃO, 2001; GERSICK et al., 1997; CHURCHILL; HATTEN, 1987). Tendo em vista a importância econômica das empresas familiares e a lacuna de estudos sobre o processo de sucessão nesse tipo de empresas, o objetivo deste estudo foi analisar e comparar os processos de sucessão de duas empresas familiares, a fim de evidenciar a importância e discutir as possíveis consequências desses processos para as empresas estudadas. O estudo é qualitativo, de caráter exploratório e descritivo, fundamentado em uma pesquisa documental em que as informações coletadas das duas empresas pesquisadas foram coligidas com o intuito de se retratar a trajetória histórica dos fatos que compõem os respectivos processos de transição.

Após um acelerado crescimento, as empresas estudadas, TAM e Azaléia, se viram surpreendidas por um problema típico das empresas familiares: o falecimento de seus fundadores que as lideraram durante décadas. O presidente da Azaléia, portador de uma grave doença, pôde ainda preparar seu sucessor por seis meses; porém a combinação de três fatores minou rapidamente as condições competitivas da organização: a diminuição da alíquota de importação de calçados, a fraqueza do dólar em relação ao real e o crescimento das exportações chinesas. Assim, após um período de profissionalização, em julho de 2007 a Azaléia foi adquirida pela Vulcabras. Já a sucessão da TAM ocorreu sem planejamento e 
preparação de um sucessor, devido à morte de seu presidente em um acidente, em julho de 2001 - período dos mais críticos da aviação mundial, e que foi agravado no Brasil pela crise vivida pela antiga líder e pelo bem-sucedido ingresso de uma nova companhia, no estilo low cost low fare.

O artigo foi assim organizado: após esta Introdução, nas Seções 2 e 3 fundamenta-se o referencial teórico sobre empresas familiares e processo de sucessão. Na Seção 4, estão os Procedimentos Metodológicos adotados. Nas Seções 5 e 6 descreve-se a trajetória da Azaléia e a da TAM. Na Seção 7 são apresentados e analisados os dois processos sucessórios. Na Seção 8, Considerações Finais, discutem-se comparativamente os dois processos, além de se sugerirem novos estudos. Por fim, seguem as Referências.

\section{EMPRESAS FAMILIARES}

Dias (1997) correlaciona a importância econômica das empresas familiares ao estímulo do mercado, à criação de empregos e à geração de renda. Para Steier, Chrisman e Chua (2004), a família é um aspecto integral da atividade econômica e da vida organizacional, de tal forma que as organizações familiares possuem importante papel na criação e no desenvolvimento de novas firmas. Afirmam que muitas organizações apresentam uma dimensão relacionada à família, desde pequenas iniciativas empreendedoras até grandes empresas, sejam elas multinegócios ou multinacionais. Como exemplo, apontam os Keiretsu e as famílias Zaibatsu no Japão, que consistem em grandes grupos familiares.

A importância e a representatividade da empresa familiar na economia nacional e mundial são frisadas com estudos sobre a quantidade de empresas familiares e sua participação no PIB de diversos países. Bornholdt (2005, p. 35) aduz que "alguns estudos consideram que a base da economia de muitos países está alicerçada nas empresas familiares típicas". Em 1998, das 300 maiores empresas privadas nacionais, 285 eram controladas por clãs. Destas, apenas $14 \%$ contavam com um presidente recrutado fora da família.

No início de 2008, das 300 maiores empresas, 265 continuam sob controle familiar, mas $32 \%$ contam com um executivo profissional na presidência. De cada cem empresas familiares, apenas 30 sobrevivem à segunda geração, apenas 15 à terceira, e não mais de quatro chegam à quarta. Empresas enormes, como Carrefour, Ford, Wal-Mart e Fiat, possuem 
ações negociadas em bolsa, mas boa parte do controle permanece com as respectivas famílias fundadoras (MEYER, 2008; RETRATO..., 2003). Steier, Chrisman e Chua (2004) argumentam que, mesmo tendo a percepção de as empresas familiares constituírem atividades econômicas e organizacionais muito difundidas, ainda são pouco estudadas. Como indicação para esse estado subdesenvolvido da pesquisa sobre empresas familiares e sua gestão, afirmam que ainda não há nem mesmo um consenso acerca de uma definição para esse tipo de negócio. Silva Júnior e Muniz (2003) aduzem que a definição de "empresa familiar" não está constituída por um corpo teórico convergente, unificado e maduro, apesar de perceberem um aumento considerável de artigos publicados sobre o tema. Segundo Bornholdt (2005, p. 34), "é relativamente intricado delimitar o que são exatamente empresas familiares".

Para Gersick et al. (1997, p. 3), “as empresas possuídas e administradas por famílias constituem uma forma organizacional peculiar, cujo caráter especial tem consequências positivas e negativas. Elas extraem uma força especial da história, da identidade e da linguagem comuns às famílias". Silva Júnior e Muniz (2003) adotam a definição de Donelley (1964), em que uma empresa é familiar quando está ligada, pelo menos, há duas gerações de uma mesma família, isto, se essa ligação resulta em uma influência recíproca, tanto na política do empreendimento, como nos interesses da família. Segundo Lodi (1978, p. 5):

\footnotetext{
No conceito de Donnelley a empresa familiar é aquela que se identifica com uma família há pelo menos duas gerações e quando essa ligação resulta numa influência recíproca. Portanto a empresa de fundador sem herdeiros não é empresa familiar, por mais que sofra as injunções de uma personalidade. E, portanto, uma empresa onde a família põe dinheiro apenas como investidora, também não é empresa familiar.
}

Essa definição também é adotada por Zahra, Hayton e Salvato (2004), ao considerarem empresas familiares como as que apresentam, pelo menos, um membro da família que possui a propriedade da firma, juntamente a várias gerações de outros familiares em posições de liderança. Já para Morck e Yeung (2004) elas devem manter o envolvimento da família nas dimensões de propriedade, gestão e expectativa de sucessão.

Bernhoeft (1989, p. 29) diz que "uma empresa familiar é aquela que tem sua origem e sua história vinculada a uma família e, ainda, aquela que mantém membros da família na administração dos negócios”. Dias (1997) corrobora ao priorizar para a definição de uma empresa familiar a forma como esta se estrutura a partir de sua fundação e como passa a ser administrada, não importando se essas empresas estão na geração de seus fundadores ou se já atingiram a geração dos sucessores.

Steier, Chrisman e Chua (2004) apontam que a influência da família em um negócio 
pode se manifestar de diferentes modos, tanto na forma como a inovação, a cultura e a sucessão são gerenciadas, quanto na maneira de se encarar a gestão. Ressaltam que, mesmo não havendo uma definição universal para a empresa familiar, existe um consenso teórico segundo o qual seu diferencial é a habilidade e as intenções da família para influenciar as decisões e o comportamento no interior da firma.

Neste estudo considera-se a definição de Bornholdt (2005, p. 34), em que uma empresa é considerada familiar quando se identificam um ou mais dos fundamentos a seguir: a família e/ou seus herdeiros mantêm o controle acionário; os laços familiares determinam a sucessão no poder; os parentes detêm cargos e funções estratégicas, como na diretoria ou no conselho da administração; as crenças e os valores da organização identificam-se com os da família; os atos dos membros da família repercutem na empresa, não importando se nela atuam; há ausência de liberdade total ou parcial de vender suas participações/quotas acumuladas ou herdadas na empresa.

\section{DAS PECULIARIDADES DE UMA EMPRESA FAMILIAR À SUCESSÃO DO SEU GESTOR}

O processo de sucessão é estratégico no escopo das organizações familiares, necessitando de um planejamento para preparar o sucessor, de tal forma que sua entrada e gestão não resultem em consequências negativas para a empresa (COSTA, 2006; CAPELÃO, 2001; GERSICK et al., 1997; CHURCHILL; HATTEN, 1987).

$\mathrm{O}$ autoritarismo pode constituir uma forma de lidar com a insegurança e o medo de assumir responsabilidade pela tomada de decisões - das quais depende o sucesso pessoal, da empresa, de outras pessoas, além de fornecedores e demais stakeholders. Devido a esse traço autoritário, torna-se difícil para o fundador abrir espaço aos filhos, que, pela natural juventude, desejam implantar mudanças, modernizar e crescer. Ao serem tolhidos, os filhos desafiam o controle dos fundadores, ou se acomodam. O ideal é que os herdeiros comecem de baixo e atuem em diversas áreas da empresa, para conhecerem o negócio como um todo. Além disso, a cada troca de posição, devem assumir maiores responsabilidades. Uma postura autoritária traz o isolamento, a impossibilidade de se compartilharem angústias e dificuldades com outras pessoas. A dificuldade de compartilhar o peso de decisões difíceis levou um empresário a afastar irmãos e cunhados do negócio - uma carga difícil de ser suportada. $\mathrm{O}$ 
processo sucessório é sempre lento, e a continuidade da empresa familiar exige transcender a figura do fundador ou gestor do momento, porém apoiando-se na unidade familiar e nos valores do negócio. A superação dessa etapa exige da empresa familiar sistemas, criatividade e um processo planejado (GARCIA, 2001; GORGATI, 2000).

Em um estudo de 500 empresas de destaque da S\&P, constatou-se que as familiares superavam em desempenho as não familiares. Conforme esse estudo, algumas das mais antigas empresas que permanecem sob controle familiar são: Cargill, Samsung, LVMH, BMW, Clarks Shoes e H\&M; e as nacionais: Gerdau, Ypioca e Cedro Cachoeira. Dentre as causas desse desempenho destacam-se: maior rapidez no processo decisório; visão de longo prazo, que pode ficar comprometida em companhias cujo controle é pulverizado e os dirigentes são trocados com frequência; c) fortalecimento da unidade dos acionistas em razão dos vínculos familiares; e possível lealdade da equipe de trabalho, em consequência dessa gestão mais estável (BERNHOEFT, 2009).

De acordo com o modelo dos três círculos, proposto por Gersick et al. (1997), a empresa familiar é representada por três dimensões independentes e sobrepostas: a gestão, a propriedade e a família (FIG. 1). Segundo Bornholdt (2005), esses termos podem ser substituídos por sistemas familiar, societário e empresarial, ou ainda família, sociedade e empresa. Associa-se, pois, o termo 'propriedade' à ideia de 'dono' e, nas empresas familiares, na maioria das vezes, dá-se à figura do 'sócio' um conceito reforçado, bem como o conceito de gestão remete a cargos de alta gerência; na prática, os membros familiares podem ter vários outros papéis dentro da organização, definitivos ou transitórios, estratégicos ou não.

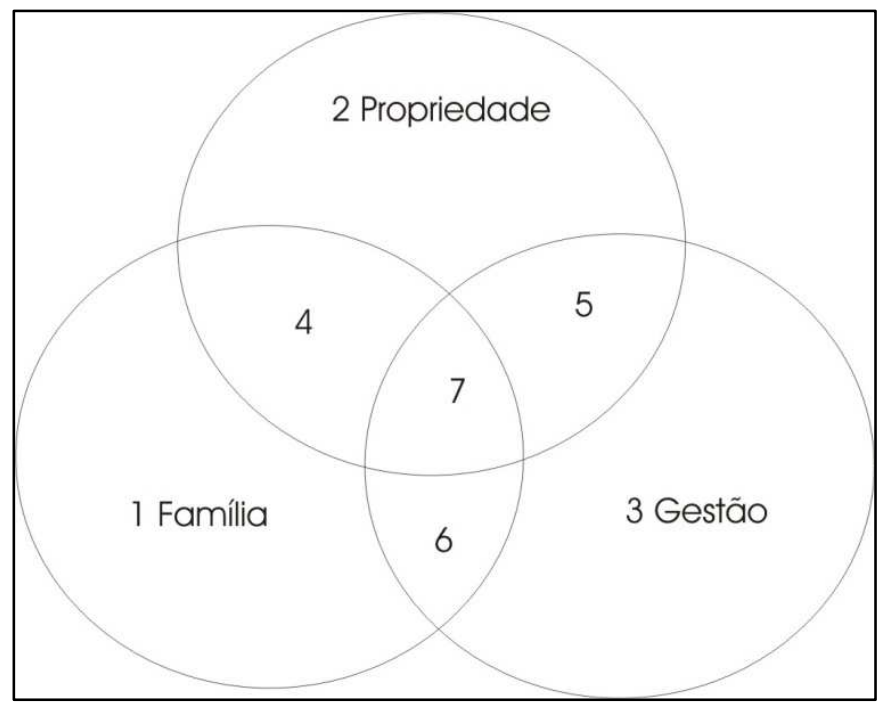

FIGURA 1: O modelo dos três círculos

Fonte: GERSICK et al., 1997, p. 6. 
Na Figura 1, o número 1 representa os familiares que não participam da gestão e da propriedade da empresa; o número 2, os proprietários do negócio que não são membros da família e nem participam da administração; o número 3 indica os gestores que não são familiares nem proprietários, normalmente, profissionais contratados; o número 4 envolve membros da família proprietários da empresa que não participam de sua gestão; o número 5, que faz interseção entre a propriedade e a gestão, representa proprietários não-familiares que gerenciam a organização; o número 6 , os membros da família que participam da gestão; e o número 7 indica um seleto grupo composto por familiares que são também proprietários e gestores (GERSICK et al., 1997).

Segundo Bornholdt (2005), as empresas familiares podem ser diferenciadas no 'sentido amplo' e no 'sentido restrito'. As empresas familiares no 'sentido amplo' são aquelas em que uma família ou grupos familiares têm participação acionaria relevante e têm um executivo, que não pertence necessariamente a uma dessas famílias, na gestão. Já no 'sentido restrito' consideram-se aquelas empresas familiares cujas organizações e administração estão sob o comando dos próprios sócios da família ou grupos familiares.

Em relação ao ciclo de vida da organização, Gersick et al. (1997) aduzem que os fundadores não são habituados a trabalhar em equipe, centralizando as decisões e fixando os valores. Silva Júnior e Muniz (2003) corroboram, apontando que, no início das atividades, a empresa familiar normalmente possui uma estrutura gerencial mais simplificada e concentrada nas mãos do fundador, mas, com o crescimento, precisa profissionalizar seu quadro de gestores. Segundo Dias (1997, p. 83) "para que as empresas familiares possam sobreviver, frente aos processos de mudanças que se fazem necessários, elas têm que criar uma identidade própria, diferenciada da do seu fundador".

Para Churchill e Hatten (1987), a gestão de empresas familiares é marcada por um processo inevitável em seu ciclo de vida e que envolve a transferência de poder entre os membros da família. Quando há a necessidade de sucessão, ocorrem, normalmente, mudanças nas formas de gestão, nas estratégias organizacionais e no controle. Normalmente, recorre-se, nessa fase, à contratação de consultores para dar suporte às mudanças a ser implantadas. Também julgam as empresas familiares adequadas para se estudarem processos de transformação organizacional, pois são marcadas pela inevitabilidade da mudança. A transferência do processo decisório e dos centros de poder nessas organizações é certa de acontecer, porque, natural e inevitavelmente, uma geração é sucessora de outra.

Gersick et al. (1997) argumentam que a sucessão é um dos momentos mais 
importantes de uma empresa familiar, por envolver sua perpetuação, pois o fundador não é eterno, mas a empresa pode viver ainda por muitos anos. Leone (1991, p. 245) define a sucessão como "o rito de transferência de poder e de capital entre a geração que atualmente dirige e a que virá a dirigir". Para Capelão e Melo (2001, p. 3), “o processo de sucessão em empresa familiar, conduzido pela manutenção de uma dominação tradicional, visa substituir um dirigente familiar por um descendente, mantendo-se a estrutura de poder vigente, baseada na pessoalidade das relações de poder exercidas". Em relação à transferência do exercício do poder, Churchill e Hatten (1987) indicam dois aspectos: a transferência do controle dos direitos da propriedade e a transferência do controle gerencial das operações e da direção estratégica do negócio (CAPELÃO, 2001).

A partir do momento em que as estratégias de controle da organização, utilizadas por uma geração de dirigentes, não são apropriadamente substituídas pelas formas de controle empregadas pelos sucessores, corre-se o risco de comprometer a sobrevivência da organização. As mudanças nas relações de poder exercidas em uma empresa familiar em decorrência do processo de sucessão fornecem uma perspectiva interessante para se averiguarem as procedências dos altos índices de descontinuidade das empresas familiares.

No estudo de Leone (1991), em 45 empresas familiares, pequenas e médias da região de João Pessoa, verificou-se que todos os dirigentes entrevistados planejam ser sucedidos por algum membro da família. Para Donnelley (1964), a sucessão tradicional - em que se escolhe um sucessor por consanguinidade - nem sempre é a melhor opção, devido à disputa de poder quando se tem mais de um herdeiro. Isso origina problemas de relacionamento entre os familiares gestores, além do que a escolha do sucessor com base nas relações de parentesco da família normalmente desconsidera fatores como eficiência e competência. Minadeo (2008) apontou 20 categorias de classificação de processos sucessórios, indicando, além disso, algumas razões das sucessões, como o crescente dinamismo da Economia, maior ritmo de mudanças no setor empresarial e a empregabilidade, que costuma trazer ofertas melhores aos gestores com bom desempenho.

Para Capelão e Melo (2001), o processo de sucessão em empresas familiares pode acarretar outro sentido, diferente da sucessão tradicional, a profissionalização da organização, pela qual se delega a gestão da empresa a um profissional selecionado por competência, enquanto a família monitora os resultados, no conselho de administração.

O exercício de poder no paradigma da empresa profissionalizada caracteriza-se pelo desenvolvimento de um sistema decisório de autonomia controlada. Ocorre uma substituição 
das ordens e interdições dos antigos dirigentes por regras e princípios interiorizados conforme a lógica da organização. A exigência para descentralizar e delegar, porém, é o planejamento e o controle (CAPELÃO; MELO, 2001, p. 3).

Oliveira (1999) aduz que a sucessão familiar exige uma análise consistente para não se avaliar de forma errônea que os herdeiros são os melhores dirigentes para a empresa. Já na sucessão profissional, a empresa passa a ser administrada por profissionais contratados, os quais também devem atuar em consonância com as características da empresa e, consequentemente, da família. Assim, Churchill e Hatten (1987) enfatizam a importância de se pesquisar a sucessão gerencial (não apenas a da propriedade) em empresas familiares, alegando que, se não houver um gerenciamento adequado do negócio, não importará quem o possua. Assim, a sucessão familiar deve ser um processo de construção do sucessor, para conciliar interesses familiares e empresariais - o que exige tempo e planejamento, bem como a definição de regras claras para a escolha do sucessor, de modo que este possua os requisitos para substituir o fundador e, ao mesmo tempo, represente os anseios de perpetuação dos valores do negócio e do patrimônio familiar, elementos que são fundamentais no processo de sucessão (CAPELÃO; MELO, 2001).

\section{PROCEDIMENTOS METODOLÓGICOS}

Este estudo é de natureza qualitativa e caráter exploratório e descritivo visto tratar de dois estudos de caso, com foco na transição do controle empresarial. Para sua realização fezse uma pesquisa documental. Para Godoy (1995, p. 21), “o exame de materiais de natureza diversa, que ainda não receberam um tratamento analítico, ou que podem ser reexaminados, buscando-se novas e/ou interpretações complementares" fundamentam a pesquisa documental. As vantagens em adotar essa estratégia consistem em possibilitar o estudo de sujeitos aos quais não se tem o acesso; os documentos são fonte rica e estável de dados; os documentos não alteram o comportamento dos sujeitos pesquisados; e ocorre baixo custo (GIL, 1991; GODOY, 1995).

Ainda quanto ao método, é um estudo de casos múltiplos, que permite uma investigação para preservar as características holísticas e significativas dos acontecimentos da vida real, entre eles processos organizacionais e administrativos. Segundo Yin (2006), usa-se 
o estudo de caso quando se quer lidar com condições contextuais, acreditando-se que elas poderiam ser pertinentes ao fenômeno de estudo. Este autor aduz cinco características gerais de um estudo de caso: deve ser significativo, ou seja, tratar de temas de interesse do público geral, apresentar assuntos subjacentes que sejam nacionalmente importantes e abordar temas teóricos importantes; deve ser "completo", apontando que o investigador gastou esforço exaustivo colecionando a evidência pertinente; deve considerar perspectivas alternativas; deve exibir suficiente evidência, de forma que um leitor com um julgamento independente possa atingir o que se pretende ilustrar; e deve ser atrativo. Esses pontos foram exaustivamente conferidos pelos autores.

Ainda quanto ao método, a pesquisa também foi histórica, cujo método pressupõe que as instituições surgem no passado, sendo preciso pesquisar suas raízes, para compreender sua natureza e função. $\mathrm{O}$ método consiste em investigar acontecimentos, processos e instituições do passado para verificar sua influência no presente (LAKATOS; MARCONI, 1991). Além disso, pode-se aduzir que o acompanhamento das empresas ao longo do tempo, no horizonte de alguns anos, em uma linha de pesquisa focada em história empresarial, torna mais robusta a difícil elaboração dos processos de transição analisados.

As fontes deste estudo foram a) imprensa especializada: impressa, Revista Exame; textos online de Valor Econômico, Folha de São Paulo, Isto É Dinheiro, Portal Exame; b) banco de dados de fusões e aquisições nacionais de um dos autores; c) artigos, livros e dissertações sobre sucessão familiar, as empresas envolvidas, bem como sobre seus respectivos setores de atividade.

As empresas escolhidas como sujeitos de pesquisa foram a TAM, a principal companhia aérea nacional na atualidade, e a Azaléia, uma das principais empresas calçadistas do país. Os dados coletados foram analisados qualitativamente. Fez-se uma descrição da trajetória e do processo de transição de ambas as empresas e, posteriormente, uma análise comparativa desses processos. Em síntese, os dados secundários - tanto acadêmicos quanto da imprensa - foram coletados, analisados e comparados ao longo do tempo e, assim, construíram os processos de transição objeto do estudo.

\section{TRAJETÓRIA DA AZALÉIA}




\subsection{O crescimento da Azaléia na gestão do fundador}

A Azaléia foi fundada em 1958 por Arnaldo de Paula, Nestor de Paula, Theno José Berlitz, Nelson Lauck e Arlindo Lauck, como Berlitz, Lauck e Cia. Ltda. As primeiras marcas foram Laika e Néctar - substituídas por Azaléia em 1965. Nestor de Paula destacou-se pelo perfil empreendedor e profissionalizante; estruturou a área financeira; racionalizou a produção; desenvolveu os departamentos de compras, almoxarifado e administrativo. Inventou um sistema de produção de solados para calçados, patenteado pela empresa. Foi dele a decisão de instalar fábricas na Bahia. O Polo Calçadista da Bahia - apesar de surgido nos anos 60 - apenas se consolidou com a vinda de grandes fábricas nos anos 90, sendo a Azaléia uma das pioneiras, instalando-se em Itapetinga e criando oito mil empregos; essa unidade, aberta em 1997, constituiu o principal investimento da cidade; outras 17 foram instaladas em cidades vizinhas. Algumas empresas (Alpargatas, Agabê, Pé de Ferro e Azaléia) anunciaram planos de expansão no Nordeste, em detrimento de suas operações no Sul e Sudeste. (RIBEIRO, 2003; ROCHA; VIANA, 2006; RODRIGUES, CRAIDE E TUDE, 2007).

A marca Olympikus surgiu em 1975, para contornar o problema da sazonalidade do calçado feminino e descontinuada em 1989, pois o tênis vulcanizado estava ultrapassado pela sola injetada em poliuretano. A publicidade de lançamento da marca ficou a cargo da agência Jotabê, e, dadas as limitações orçamentárias, foi escolhido o Programa Sílvio Santos para o evento; além disso, a agência usou a novela Dancing Days para a marca Azaléia - cujo logo também foi de sua lavra. A Jotabê atendeu a Azaléia por quinze anos, e seu fundador, Jones Batista, sempre admirou a figura de Nestor de Paula, que durante anos sonhou em ser a maior empresa do setor no país. Houve posteriores investimentos em projeto, produção e gestão, e a Olympikus voltou a ser alvo de campanhas publicitárias em 1994 - após três anos com apenas um produto sendo comercializado -, em uma época em que poucos fabricantes do setor investiam em propaganda nacional. E, em dois anos, a marca Olympikus chegou à posição de maior marca de tênis no Brasil, em receitas, com um valor de cerca de $\mathrm{R} \$ 250$ milhões, correspondente à metade do faturamento da Azaléia, com a venda de quase oito milhões de pares. As receitas da empresa subiram de R \$ 272 milhões em 1992 para $\mathrm{R} \$ 539$ milhões em 1996. No período, a rentabilidade passou de $R \$ 12$ para $R \$ 61$ milhões. Após uma transição de cinco anos, a empresa passou a vender $100 \%$ de produtos com suas próprias marcas. A empresa contava com 20 lojas franqueadas no Chile com as marcas Azaléia e Dijean. Ainda a 
respeito dessa incursão no varejo, a Azaléia adotou o modelo de lojas próprias e exclusivas, com as bandeiras Azaléia e Olympikus, chegando a 18 lojas próprias e 71 exclusivas. O Chile era o principal mercado, com seis lojas próprias e 17 exclusivas. Os outros mercados eram: Peru, Colômbia, México e República Checa (CAETANO, 1997; MATURO, 2004; D’AMBROSIO, 2005; MACHADO; SANTOS, 2007).

Em 1991, a empresa fez uma pesquisa interna para descobrir de que o pessoal necessitava, e as principais respostas foram: saúde, casa própria, educação, transporte e segurança. Diante disso, foi contratado Ernest Sarlet, filósofo e sociólogo, que idealizou o projeto Azaléia Construindo o Futuro, lançado em 2001, e inspirado no fato de o maior fabricante de calçados mundial, a Bata, afirmar que seu crescimento se deveu à criação de um colégio para capacitar seu pessoal, em 1925 (BERNARDI, 1997). A Bata, nascida na Tchecoslováquia, fora desapropriada pelo governo. O filho do fundador se mudou para Toronto, criando uma nova empresa, que, antes da Segunda Guerra Mundial, já criara fábricas na África e Ásia, liderando a produção mundial de calçados. Nos anos 90, a Bata contava com 80 fábricas, abrindo o caminho para outras, como a Nike, que cresceram fazendo toda a sua produção na Ásia (CALORI et al., 2000). Com esse projeto, a Azaléia passou a ter planos próprios de saúde, habitação, educação e transporte para funcionários e familiares. Criou, na própria sede, diversos centros de educação, tradicionais, profissionalizantes e de idiomas. Em resultado do programa, o índice de retrabalho baixou de dois para quase zero em cada mil pares; a rotatividade caiu de $0,7 \%$ para $0,5 \%$ e o absenteísmo foi reduzido à metade (BERNARDI, 1997). Passou a custear $80 \%$ do custo de duas disciplinas dos funcionários em universidades - com 260 funcionários utilizando esse benefício. Além disso, passou a oferecer refeições aos que trabalham e também estudam. Criou uma creche para 800 crianças, operando 24 horas por dia. Foi criado um plano de participação nos resultados, ligado às metas: em 1996, a empresa distribuiu R\$ 14 milhões (GOMES, 1997). Sobre esse projeto, para Ribeiro (2003), trata-se de uma organização com potencial na esfera social, por suas características de Responsabilidade Social, no âmbito interno e no externo.

\subsection{Sucessão e mudanças na Azaléia}

Em 2004, falece o Presidente, Nestor Herculano de Paula, aos 66 anos. A Presidência 
passou a Antonio Britto, ex-governador gaúcho (1995-1998), contratado pelo próprio fundador, seis meses antes, pois Nestor estava com câncer e preparou a sucessão. Britto se aproximara da Azaléia em 1999, como consultor da Associação Brasileira da Indústria de Calçados. A empresa já fizera uma tentativa de sucessão, ao contratar Gumercindo Neto em 2000; porém este saiu da empresa, indo para a rival Alpargatas. A primeira tarefa do novo Presidente foi uma descentralização, pois o fundador era centralizador (NAIDITCH, 2004).

Em 2004, a Azaléia produziu 35,6 milhões de pares, 11,9\% a mais do que em 2003. A receita foi de $\mathrm{R} \$ 992,4$ milhões, crescendo $19,8 \%$ sobre o ano anterior. O lucro subiu $71 \%$, chegando a R\$ 17 milhões. Em 2005, fechou a fábrica gaúcha de São Sebastião do Caí, demitindo os 800 funcionários. A Azaléia contava com 28 fábricas, sendo cinco no Rio Grande do Sul, 18 na Bahia e cinco em Sergipe. A Azaléia vendeu a Energética Campos de Cima da Serra, com participações em cinco hidrelétricas, por R $\$ 21$ milhões. As receitas em 2005 foram de cerca de $\mathrm{R}$ \$ 1 bilhão, crescendo 1,8\% em relação ao ano anterior e com lucros de R \$ 27,7 milhões. Foram vendidos 24,9 milhões de pares no mercado interno e exportados 6,6 milhões de pares. As exportações caíram 15,4\% em valor e 25,8\% em volume. A Azaléia alugou fábricas no polo chinês Dong Huan, para produzir calçados vendidos nos EUA e no Brasil. Essa estratégia foi a única encontrada para não perder seu maior mercado, o norteamericano, que consome dois dos 14 bilhões de calçados produzidos anualmente no mundo. Em 2006, fechou-se uma fábrica em Itaporanga D’Ajuda (Sergipe), com 230 demissões (BUENO, 2005a; BUENO, 2005b; BUENO, 2005c; CUNHA, 2005; BARONE, 2006; NAKAMURA, 2007; GÓMEZ, 2007).

Ao final de 2006, Britto renunciou por julgar encerrada a transição. O cargo passou interinamente a Adelino Colombo, que presidia o Conselho de Administração e que criara a rede varejista com seu nome. A Azaléia alcançou lucro de R\$ 65,4 milhões em 2006, com receita de R \$ 982,9 milhões, uma queda de 2,7\% ante a de 2005. A produção alcançou 29,39 milhões de pares, volume $8,8 \%$ inferior à de 2005 . As exportações foram de 4,4 milhões de pares, $33 \%$ a menos que no ano anterior; as receitas com exportações caíram 24,5\%, para US\$ 36 milhões. O endividamento financeiro da companhia em 2006 subiu de R\$ 96,7 milhões para R\$ 141 milhões (BUENO, 2006; NAKAMURA, 2007). 


\subsection{Aquisição da Azaléia pela Vulcabras}

Em julho de 2007, a Vulcabras adquiriu 22,67\% do capital total da Azaléia e 22,67\% das preferenciais. Logo em seguida, adquiriu 99,74\% das ordinárias, passando a deter seu controle, com 51,28\% do capital. A holding Pilar Empreendimentos Imobiliários, que possuía 99,16\% das ações ordinárias da Azaléia, era das famílias De Paula e Volkart. A primeira tinha 52\% da Pilar e a segunda, 48\%. O valor do negócio foi de $\mathrm{R} \$ 342,388$ milhões. (COMPRA..., 2007).

Os gêmeos Pedro e Alexandre Grendene iniciaram os negócios em 1972, produzindo embalagens plásticas para garrafões de vinho, depois lançaram os calçados plásticos Melissa sucesso nos anos 80. Separaram-se, ficando a Grendene com Alexandre (sendo Pedro detentor de $20 \%$ das ações) e a Vulcabras com Pedro. A Grendene detinha as marcas Melissa e Ryder, com receitas de $\mathrm{R} \$ 1,1$ bilhão em 2006, e 19,5 mil funcionários. Cerca de $90 \%$ da receita da Vulcabras provém dos produtos Reebok, cujo contrato de 14 anos estava para ser encerrado em 2012, o que lhe traria uma vulnerabilidade, já ocorrida ao término de seu licenciamento com a Adidas. Assim, a compra da Azaléia foi defensiva, para proteger-se com a marca Olympikus da possível perda da Reebok (CARVALHO, 2007; KROEHN, 2007).

Com a compra da Azaléia, a Vulcabras decidiu fortalecer a Olympikus na Argentina, cujo mercado de tênis premium é de 15 milhões de pares por ano, contra 18 milhões no Brasil. Assumiu a distribuição e boa parte dos artigos passou a ser produzida pela Indular, adquirida pela Vulcabras em 2007. Antes da aquisição da Azaléia, a Vulcabras já garantia um terço do seu faturamento com vendas no país vizinho (NAKAMURA, 2008).

\section{TRAJETÓRIA DA TAM}

Rolim começou sua vida profissional, trabalhando como assistente de mecânico e office-boy. Aos 21 anos ingressou em uma recém-criada empresa de táxi aéreo. A TAM surgiu nos anos 60 como empresa de táxi aéreo, sendo o Comte. Rolim um de seus pilotos. Após algumas experiências na Amazônia como empresário, nos anos 70 retorna à TAM como um de seus sócios, e, em meados da década, a empresa ingressa no recém-criado sistema de 
transporte aéreo regional, tendo a VASP como minoritária. Rolim é reconhecido como dos maiores empresários nacionais. Em 1989 lançou iniciativas que o tornaram famoso: o famoso tapete vermelho, a recepção dos passageiros pessoalmente à porta dos aviões e a realização do check-in de alguns passageiros em Congonhas (MINADEO; RAPHAEL; CUNHA, 2003; UBINHA; PEDROSO; CASSIANO, 2008).

Quando convidado a compor o grupo dos fundadores da TAM, Rolim não dispunha do capital. Pensava em custeá-la deixando de pagar o seguro dos aviões. Mudou de ideia e pagou as apólices na véspera do dia em que um dos jatos da empresa caiu na baía da Guanabara, vindo do aeroporto Santos Dumont. Com os recursos obtidos da seguradora, Rolim pagou as ações. Em 1975, o Governo organiza o Sistema Integrado de Transporte Aéreo Brasileiro para desenvolver a aviação regional, atribuindo à TAM a melhor aviação área do País: o interior de São Paulo, o norte do Paraná e o sul do Mato Grosso - base que suscitou o desenvolvimento da empresa (THÉRY, 2003).

A TAM se preparara para a privatização da VASP. Vendo, porém, que esta não era factível, canalizou recursos para seu crescimento, pela compra de uma frota de aviões Fokker 100 - o que lhe propiciou um sólido crescimento. Em 1996, adquiriu a Líneas Aéreas Paraguayas, como única forma de acesso a linhas internacionais, uma vez que as linhas partindo do Brasil eram todas detidas pela Varig. Em 1996, a TAM ingressou no mercado internacional adquirindo cinco Airbus A330-200 e sessenta A320 (para substituir os Fokker100 nos vôos domésticos), quebrando o monopólio tanto da Varig como da Boeing no mercado brasileiro. Em 1997, 27\% das ações preferenciais da TAM foram vendidas a fundos de investimentos, por R $\$ 80$ milhões. Em 1998, arrendou 38 unidades do Airbus, expandindo a oferta de assentos. Ao final desse ano, inicia voos aos EUA e, no ano seguinte, lança sua primeira rota à Europa. Em 2001, a TAM inaugurou seu Centro de Manutenção em São Carlos (MINADEO; RAPHAEL; CUNHA, 2003; THÉRY, 2003).

Após a morte do fundador da TAM, na queda de um helicóptero em julho de 2001, seu cunhado Daniel Mandelli assumiu a Presidência Executiva e a do Conselho; a empresa enfrentava uma grave crise financeira. Mandelli concluiu que seria preciso mudar o que o fundador mais prezava: a qualidade do serviço, ampliando os assentos pela diminuição do espaço nos aviões e simplificando o serviço de bordo. Algumas decisões contrariaram o Conselho, e Mandelli foi demitido após dois anos no cargo. Mandelli estava com 49 anos de idade, formado em administração pela FGV, e trabalhava na TAM desde 1973, amigo do Comte. Rolim desde a infância. Luiz Eduardo Falco, após 20 anos de trabalho na empresa, 
saiu da TAM, com a escolha de Mandelli. Passou a presidir a área de telefonia celular da Telemar. Formado em Engenharia pelo ITA, estava com 41 anos. Em alguns anos, a Telemar foi renomeada Oi, com Falco na Presidência. Pode-se supor que Falco teria podido suceder Rolim, porém foi natural que buscasse outros rumos à sua carreira (CORNILS, 2001; CORRÊA, 2001; CAMARGOS, 2007).

Em 2002, devido à crise na aviação provocada pelos incidentes do Onze de Setembro, a TAM suspendeu os voos a Frankfurt, Zurich e Montevidéu, deixou de implementar os voos a Madrid, e diminuiu as frequências a Buenos Aires e Miami. A TAM perdeu seu vicepresidente comercial internacional, Rubel Thomas, e o de RH, Jean Duboc. Em três anos cortou $30 \%$ do pessoal e aboliu a classe executiva nos voos internos, ampliando a oferta de assentos. Em 2003, a TAM e a Varig iniciaram um acordo de code-sharing, visando à redução de custos e também, como um possível primeiro passo, visando à fusão das duas empresas um sonho do Comte. Rolim (FUTEMA, 2002; MINADEO; RAPHAEL; CUNHA, 2003; VARGA, 2003; LETHBRIDGE, 2004).

Martinez e Balarin (2003) e Futema (2003a) apontam que Marco Antonio Bologna assumiu a Presidência da TAM, cerca de seis meses após a saída de Mandelli, ocorrida em razão de divergências em relação à possível fusão com a Varig. A Presidência fora assumida interinamente por Antonio Luiz Teixeira de Barros Júnior, amigo da família. Futema (2003b) aponta que Bologna ingressara na TAM em 2001, chamado pelo fundador para a vicepresidência financeira. Futema (2004) e Goy (2004) complementam, apontando que Henry Philippe Reichstul assumiu a Presidência do Conselho, ficando Bologna na Presidência executiva e não mais acumulando os dois cargos, para aprimorar a governança corporativa. Esse fato corrobora Camargos e Minadeo (2007) que apontam estar nesse tema algumas causas da crise da Varig, que, por exemplo, trocara cinco vezes de Presidência em seis anos, sinalizando descontinuidade na implantação de programas e uma não renovação de suas técnicas de gestão, que teriam sido vitais à sua sobrevivência.

Em julho de 2005, a TAM captou de R 548 milhões em Bolsa, encerrando-se o ciclo de problemas desencadeados com o falecimento do Comte. Rolim, a crise aérea, o ingresso da Gol e o aumento dos preços do petróleo. Entre 2001 e 2002 houve R\$ 622 milhões de prejuízos, e coube a seu sucessor, Daniel Mandelli, tomar as medidas mais amargas, pois a oferta de serviços premium a um preço superior passou a ser inviável nesse novo ambiente. $\mathrm{O}$ compartilhamento de voos com a Varig gerou $\mathrm{R} \$ 250$ milhões em economias para a TAM que sabia desde o início que seria impossível a concretização da fusão. Durante a época desse 
acordo, a TAM fez os cortes necessários em sua estrutura de custos, e a diferença em relação à Gol caiu de 32\% em 2003 para 14\% em 2005 (LETHBRIDGE, 2005).

Em 2005, a TAM lucrou R \$ 187,4 milhões sobre receitas de $\mathrm{R} \$ 5,9$ bilhões. Em 2006, a gerência de marketing foi assumida por Manuela Amaro Mugnaini, sobrinha do fundador. Segundo depoimentos do Presidente e dessa nova gestora, ainda que seja impossível retornar aos padrões de serviços do tempo do fundador, em razão dos custos, também é impensável que a marca TAM sobreviva com barrinhas de cereal e saquinhos de amendoim. Um dos esforços para combater essa crise de identidade foi o lançamento de um novo modelo tarifário, com cinco padrões diferentes de preços, associados a diversos níveis de serviços. Além disso, a empresa contratou 1.300 funcionários que eram terceirizados e pretendia contratar outros 4.500 (HERZOG, 2006).

Em 2007, a TAM substituiu a Presidência, entrando David Barioni Neto, oriundo da rival Gol. Bologna havia ficado desgastado em consequência da crise aérea, deflagrada com um acidente da Gol em setembro do ano anterior e com a queda de um Airbus da TAM em julho de 2007. Houve descontentamento no Conselho com a condução da crise por Bologna. Barioni iniciara a carreira como piloto, tendo sido um dos responsáveis pela boa gestão da crise na Gol por ocasião do citado acidente, além de responder pelas operações por quase seis anos. Barioni trouxe um de seus auxiliares, Fernando Sporleder, para a vice-presidência de operações. Bologna esteve por um tempo na Presidência da construtora WTorre e retornou à TAM em 2009, na Presidência da TAM Aviação Executiva (BALARIN; CAMPASSI, 2007; CARVALHO; ONAGA, 2007; ONAGA, 2009).

\section{ANÁLISE DOS PROCESSOS DE TRANSIÇÃO}

\subsection{Processo da Azaléia}

A Azaléia iniciou-se em 1958 e, em algumas décadas, atingiu a posição de uma das maiores produtoras brasileiras de calçados. Com o falecimento de seu fundador e a consequente profissionalização da gestão, coincidiram os problemas derivados de um delicado tripé: a queda das alíquotas de importação de calçados, a competitividade do calçado chinês e 
a força da moeda brasileira em relação ao dólar. Esses fatores corroeram as vantagens de diversas indústrias, notadamente a de calçados.

O fundador era centralizador porque tanto o sucessor quanto o outro profissional contratado anteriormente para a tarefa de direção vieram de fora da empresa, em razão de suas habilidades técnicas e de organizador. $\mathrm{O}$ fundador não soube criar ou formar alguém que viesse a sucedê-lo, apesar dos investimentos em treinamento do pessoal em geral e dos executivos em particular. Seu estilo de gestão também seguiu a característica one man show, que não permite o surgimento de outras lideranças, ao mesmo tempo em que está frequentemente em evidência na imprensa, inclusive com vários anúncios de planos mirabolantes e que não se materializaram.

A escolha de um ex-governador pelo próprio fundador como sucessor é elucidativa. Mc Cann (1992) exemplifica com a Searle, que nos anos 70 trocou sua equipe diretiva, substituindo-a por quadros egressos da administração pública, pois a FDA questionava uma série de testes da empresa. Assim, em meio à crise, a contratação dessa equipe possuía uma clara finalidade: conduzir a empresa com sucesso em meio às incontáveis negociações necessárias junto a diversas instâncias governamentais. Ora, ninguém melhor do que gestores com anos de experiência na burocracia federal, para conduzir esse processo.

Na sucessão do fundador, poderia ter sido escolhido algum executivo com experiência comprovada em reestruturação e em direção de empresas de ramos bastante variados. Cabe imaginar os eventuais motivos que levaram à escolha de um político. Ou seja, talvez o principal papel desse sucessor fosse o de pilotar uma etapa de transição, para uma futura decisão da própria empresa, como ele mesmo declarou ao se retirar, tendo cumprido a missão a ele delegada. Além disso, o fato de esse dirigente ter feito diversas declarações públicas sobre os problemas derivados das importações chinesas e do câmbio sugere que a possibilidade de obter tratamento público favorável a um importante setor da economia fosse uma das legítimas finalidades da indicação de um político de sua estatura.

Ora, diante desse complexo quadro, a venda da empresa deve ser analisada no contexto de uma empresa familiar: para os controladores do negócio, este representa a maior parte de seus ativos. Assim, diante das crescentes incertezas do setor, a profissionalização foi imediata e corretamente empreendida. Porém caberiam ao menos três opções estratégicas: a Azaléia poderia captar novos recursos em Bolsa de Valores; a empresa poderia empreender algum tipo de aliança estratégica, de modo que os acionistas trocassem suas ações controladoras da Azaléia por uma posição equitativa na nova empresa, como, por exemplo, 
sendo a Azaléia forte em calçados femininos e esportivos, e uma aliança com um grupo forte em calçados masculinos poderia fortalecer os dois lados; e a empresa poderia aprofundar a reestruturação, de modo a se tornar mais atrativa para uma futura operação, que poderia vir a ser qualquer uma das duas acima apontadas.

Os acionistas viram que a profissionalização trouxe alguns resultados, mediante corte de custos e a venda de ativos. A hipótese de ampliarem o escopo da estruturação parece impossível a um grupo ligado às famílias dos fundadores, e com inúmeros laços com funcionários antigos - ainda mais em uma empresa oriunda de uma pequena cidade, cuja economia é, em grande parte, representada pela Azaléia.

Além disso, a existência de um projeto na área da responsabilidade social, que a empresa acalentava desde 2001, também parece indicar uma adicional dificuldade para aprofundar sua reestruturação. Assim, uma solução com amplos cortes de pessoal provavelmente não teria respaldo político nesse grupo controlador - ainda que viesse a ser fundamental para a manutenção das condições de competitividade da empresa, parecendo, portanto, razoável buscar outras opções estratégicas.

A possibilidade de continuarem como controladores do negócio pareceria de elevado risco. Por exemplo, as dificuldades que a Olympikus enfrentou e continua enfrentando são enormes, ao concorrer com empresas de atuação global. É com base na visão desse contexto que os resultados obtidos por essa marca nacional precisam ser devidamente aquilatados.

Além disso, cabe ressaltar que a situação cambial não apresentava horizonte de reversibilidade, ou seja, o tempo atuava contra o futuro da organização, sendo razoável supor o elevado grau de risco para o patrimônio dos acionistas, representado pelo fato de deter quase todos seus ativos atrelados ao difícil negócio calçadista.

Dois eventos contribuíram à decisão de venda da Azaléia: a Samello, uma das líderes brasileiras em calçados masculinos, com décadas de tradição, e já em sua terceira geração, suspendeu as atividades em outubro de 2006; e a Reichert descontinuou suas atividades, demitindo todos os trabalhadores, em várias fábricas gaúchas, apesar de ter exportado no ano anterior US\$ 85 milhões; era a maior exportadora de calçados femininos do país (GÓMEZ; CAMPASSI; MANDL, 2006; BUENO, 2007; BUENO; TOTTI, 2007).

Assim, a venda das ações pode ter representado a aceitação de uma proposta razoável, que teve o efeito de ser bem mais rápida do que os trâmites para efetuar a busca de capitais em Bolsas de Valores, ou os procedimentos necessários para se buscar algum tipo de associação. Por outro lado, o grupo adquirente detém a marca Vulcabras, além de ser 
licenciado da Reebok, reunindo as condições para garantir a melhor continuidade possível dos negócios da Azaléia. Finalmente, o fato de dois irmãos gêmeos controlarem, respectivamente, a Vulcabras e a Grendene, faz vislumbrar uma possível fusão entre essas duas empresas, criando, desse modo, um player de porte global na produção de calçados. Aliás, o fato de Pedro Grendene - controlador da Vulcabras - deter $20 \%$ da Grendene reforça essa possibilidade.

Além da força da marca Azaléia, um fator que levou à sua aquisição foi sua internacionalização - as fortes exportações e a existência de uma rede de lojas em vários mercados. A atuação de um fabricante de calçados no varejo significa a possibilidade de estar menos vulnerável à concorrência, pelo fato de possuir um canal de distribuição exclusivo para seus produtos, além do fato de contar com uma forma privilegiada de acompanhar a evolução do comportamento do consumidor.

\subsection{Processo da TAM}

A TAM originou-se nos anos 70, sob a direção do Comte. Rolim. Por meio de uma liderança empreendedora, conseguiu adquirir uma empresa criada por sócios de interesses diversos; obteve licenças governamentais, nacionais e depois internacionais; e superou a Varig - que detinha décadas de liderança. O falecimento de Rolim ocorreu no pior momento possível: em razão da situação da aviação mundial; do quadro doméstico, pois a Varig se encontrava em crise havia diversos anos, e Rolim pessoalmente desejava algum tipo de fusão com essa empresa; e, nesse ano, do ingresso da Gol no mercado.

Desse modo, a sucessão por um familiar foi a solução mais natural, tendo Mandelli o cuidado de evitar imitar o estilo do fundador, sabendo manter-se reservado, até por lhe caber a tomada de algumas decisões amargas. Nessa primeira etapa, que dificilmente poderia ter sido diferente devido às circunstâncias, a TAM perdeu vários executivos importantes, porém Mandelli conduziu a empresa rumo a um necessário corte de custos, visando manter sua sobrevivência, no conturbado panorama da aviação.

O mandato de Mandelli ficou inviável pela impossibilidade da fusão com a Varig e da impopularidade do gestor que corta custos. O fato de um amigo da família ocupar interinamente a Presidência por seis meses é sinal de sua boa gestão, havendo tempo para a 
escolha de um sucessor com outro perfil: o de concluir a superação da crise e de preparar a empresa para a próxima etapa de crescimento. $\mathrm{O}$ fato de Bologna ter sido escolhido pelo próprio Rolim foi fundamental para assumir a Presidência. A liderança da TAM no mercado interno, coincidindo com o aprofundamento da crise da Varig, o crescimento da Gol e o lançamento de novas linhas internacionais pela TAM, foi a etapa seguinte, já na gestão de Bologna. Balarin e Campassi (2007) destacam que Bologna abriu o capital da empresa e diversificou as fontes de financiamento, mas os serviços de bordo ficaram mais escassos, e a imagem da empresa se ressentiu em consequência da crise aérea e do acidente, o que culminou com a entrada de Barioni, encerrando um conturbado processo de transição.

A presença de uma nova gestora de marketing, da família, talvez possa continuar a caracterizar a empresa como familiar. O pacote de medidas anunciado por ela é associado à retomada da imagem de liderança da marca e, o mais importante, sendo acompanhado por resultados financeiros consistentes e pela entrada de um novo Presidente, não mais focado nos resultados financeiros de curto prazo ou na sobrevivência, até pelo fato de a crise ter sido superada em uma gestão anterior à sua entrada.

\section{CONSIDERAÇÕES FINAIS}

Os processos de transição observados na Azaléia e na TAM guardam correlações, porque são empresas que enfrentaram a morte de seus respectivos fundadores, ambos do tipo que imprimiram fortes características pessoais aos negócios por eles criados. Nenhum deles preparou sucessores familiares, o que seria o segundo estágio na visão do Referencial Teórico. Além disso, a visão de Donnelley corroborada por Lodi - de que uma empresa necessita estar pelo menos há duas gerações sob controle familiar - aplica-se à TAM, porém não à Azaléia, que foi vendida pouco tempo após a morte do fundador, havendo um interregno de Presidência ocupada por um profissional. Nessa companhia, em razão de estar com uma doença, o próprio fundador preparou um sucessor, escolhendo uma pessoa com origem na política e posterior experiência empresarial, e que profissionalizou a empresa, preparando-a para uma venda ou possível abertura de capital.

Na TAM, o trauma foi maior, devido ao inesperado. A transição foi dividida em três fases: um membro da família assume - em consequência do fator surpresa - e implementa as 
mudanças mais urgentes, preparando o caminho para um profissional da área financeira assumir o comando, visando à abertura de capital e à sobrevivência da empresa em meio à forte crise que se abateu sobre o setor. Depois, superados os principais problemas, um novo Presidente direciona a empresa no caminho da recuperação da imagem de liderança da marca na prestação de serviços de qualidade - tarefa difícil para um Presidente com ênfase em finanças e que tropeçará na condução da difícil crise após o acidente de Congonhas de julho de 2007.

As duas transições foram dificultadas pelos momentos críticos vividos em seus respectivos setores de atuação e pela difícil conjuntura mundial de ambos.

Neste estudo propiciou-se o enriquecimento da comparação de companhias que viveram processos com algumas semelhanças; além disso, obrigou-se a um aprofundamento teórico que pode ser aplicado em novos textos, em consonância com os estudos dos autores.

As limitações do estudo se prendem ao uso de dados secundários, em razão da carência de recursos para abordar os diretores das duas empresas analisadas, visando captar dados primários. Novos estudos poderiam enfocar análises mais amplas de sucessões de diversas empresas, tanto de setores diversos quanto do mesmo setor.

\section{Referência}

BALARIN, R.; CAMPASSI, R. TAM faz troca de comando e quer resgatar imagem. Valor Econômico, São Paulo, 29 nov. 2007.

BARONE, V. Azaléia cria A/Z para equilibrar desempenho nas exportações. Valor, 3 jul. 2006. Disponível em: < http://www.valor.com.br >. Acesso em: 01 ago. 2007.

BERNARDI, M. A. Lar, doce escritório. Portal Exame, São Paulo, 15 jan. 1997. Disponível em: <http://www.exame.com.br> Acesso em: 1 ago. 2007.

BERNHOEFT, R. Crise leva famílias de volta para a gestão das empresas. Valor Econômico, São Paulo, 30 jan. 2009.

BERNHOEFT, R. Empresa Familiar: sucessão profissionalizada ou sobrevivência comprometida. 2. ed. São Paulo: Nobel, 1989.

BORNHOLDT, W. Governança na empresa familiar: implementação e prática. Porto Alegre: Bookman, 2005.

BUENO, S. Azaléia fecha unidade no RS e demite 800 funcionários. Valor, 06 dez. 2005a. Disponível em: < http://www.valor.com.br >. Acesso em: 1 ago. 2007. 
BUENO, S. Azaléia vende sua controlada ECCS para Brascan e retira-se do setor de energia. Valor, 5 out. 2005b. Disponível em: < http://www.valor.com.br >. Acesso em: 1 ago. 2007.

BUENO, S. Britto deixa o comando da Azaléia. Valor, São Paulo, 5 dez. 2006. Disponível em: < http://www.valor.com.br >. Acesso em: 1 ago. 2007.

BUENO, S. Novas unidades farão Azaléia elevar capacidade em 30\%. Valor, 8 mar. 2005c. Disponível em: < http://www.valor.com.br >. Acesso em: 1 ago. 2007.

BUENO, S. Para funcionários da Reichert, deixar cidade é alternativa. Valor, 30 maio 2007. Disponível em: < http://www.valor.com.br >. Acesso em: 1 ago. 2007.

BUENO, S.; TOTTI, P. Maior exportadora do Brasil de calçados fecha as portas. Valor, 29 maio 2007. Disponível em: < http://www.valor.com.br >. Acesso em: 1 ago. 2007.

CAETANO, J. R. Da tumba para o pódio. Portal Exame, 24 jul. 1997. Disponível em: <http://www.exame.com.br> Acesso em: 1 ago. 2007.

CALORI, R; MELIN, L.; ATAMER, T.; GUSTAVSSON, P. Innovative International Strategies. Journal of World Business, v. 35, n. 4, p. 333-354, 2000.

CAMARGOS, D. O desafio de suceder lendas. Revista Exame, v. 41, n. 18, p. 30-34, 26 set. 2007.

CAMARGOS, M. A.; MINADEO, R. Fusões e aquisições na aviação civil: uma análise da aquisição da Varig pela Gol. In: ENCONTRO NACIONAL DOS CURSOS DE GRADUAÇÃO EM ADMINISTRAÇÃO, 18, 2007, Cuiabá. Anais Eletrônicos... Cuiabá: ANGRAD, 2007. CD-ROM.

CAPELÃO, L. G. F. A genealogia do poder no processo de sucessão em empreendimentos familiares brasileiros: o caso das indústrias Filizola S.A. 2001. 129 f. Dissertação (Mestrado em Administração) - Departamento de Ciências Administrativas, Universidade Federal de Minas Gerais, Belo Horizonte.

CAPELÃO, L. G. F.; MELO, M. C. O. L. Relações de Poder no Processo de Sucessão em Empresa Familiar: o caso das Indústrias Filizola S.A. In: ENCONTRO NACIONAL DE PÓS GRADUAÇÃO EM ADMINISTRAÇÃO, 25, 2001, Campinas. Anais Eletrônicos... Campinas: ANPAD, 2001. CD-ROM.

CARVAlHO, D. Dois irmãos contra a China. Portal Exame, 26 jul. 2007. Disponível em: <http://www.exame.com.br. $>$ Acesso em: 1 ago. 2007.

CARVALHO, D.; ONAGA, M. Chamaram o piloto. Revista Exame, v. 41, n. 908, 19 dez. 2007, p. 62-64.

CHURCHILL, N.; HATTEN, K. Non-market-based transfers of wealth and power: a research framework for family businesses. American Journal of Small Business, [s.1.], fall, 1987.

COMPRA da Azaléia custará R \$ 387,541 milhões à Vulcabras. Portal Exame, 1 ago. 2007. Disponível em: 〈http://www.exame.com.br〉. Acesso em: 2 ago. 2007. 
CORNILS, P. Falco deixa a TAM e assume o comando da Telemar PCS. Valor, 20 set. 2001. Disponível em: < http://www.valor.com.br >. Acesso em: 8 ago. 2007.

CORRÊA, C. Daniel Mandelli assume a TAM sem surpresas. Valor, 11 jul. 2001. Disponível em: < http://www.valor.com.br >. Acesso em: 8 ago. 2007.

COSTA, A. D. Sucessão e sucesso nas empresas familiares. Curitiba: Juruá, 2006.

CUNHA, L. Azaléia vai à China. Isto É Dinheiro, São Paulo, 21 dez. 2005. Disponível em: <http://www.terra.com.br/istoedinheiro>. Acesso em: 2 ago. 2007.

D’AMBROSIO, D. Calçadista adota loja própria para crescer no exterior. Valor, 12 jan. 2005. Disponível em: < http://www.valor.com.br >. Acesso em: 01 ago. 2007.

DIAS, T. M. C. Baiana de Acarajé: uma empresa familiar de sucesso. 1997. 165 f.

Dissertação (Mestrado em Administração) - Núcleo de Pós-Graduação em Administração, Escola de Administração da Universidade Federal da Bahia, Salvador.

DONELLEY, R. G. The family business. Harvard Business Review, [s.1.], v. 42, n. 4, p. 94105, jul.-ago. 1964.

FUTEMA, F. Marco Bologna assume presidência da TAM. Folha, 19 dez. 2003b. Disponível em: < http://www.valor.com.br >. Acesso em: 18 nov. 2007.

FUTEMA, F. Presidente da TAM deixa o cargo e fusão com a Varig fica mais distante. Folha online, 14 ago. 2003a. Disponível em: < http://www.valor.com.br >. Acesso em: 18 nov. 2007.

FUTEMA, F. Reichstul assume lugar de Bologna no conselho da TAM. Folha, 20 dez. 2004. Disponível em: < http://www.valor.com.br >. Acesso em: 18 nov. 2007.

FUTEMA, F. Vice-presidente da área internacional deixa a TAM após corte em voos. Folha, 25 jan. 2002. Disponível em: < http://www.valor.com.br >. Acesso em: 18 nov. 2007.

GARCIA, V. P. Desenvolvimento das famílias empresárias. Rio de Janeiro: Qualitymark, 2001.

GERSICK, K. E. ; DAVIS, J. A.; HAMPTON, M. M.; LANDSBERG, I. S. De geração para geração: ciclos de vida das empresas familiares. São Paulo: Negócio, 1997.

GIL, A. C. Técnicas de pesquisa em economia. São Paulo: Atlas, 1991.

GODOY, A. S. Pesquisa qualitativa: tipos fundamentais. Revista de Administração de Empresas - RAE, São Paulo: FGV, v. 35, n. 3, p. 20-29, maio-jun. 1995.

GOMES, M. T. Azaléia. Portal Exame, São Paulo, 22 out. 1997. Disponível em: <http://www.exame.com.br >.Acesso em: 1 ago. 2007.

GÓMEZ, N. Azaléia diversifica linhas de produtos. Valor, 18 jan. 2007. Disponível em: < http://www.valor.com.br >. Acesso em: 1 ago. 2007. 
GÓMEZ, N.; CAMPASSI, R.; MANDL, C. Samello pede recuperação judicial. Valor, 16 nov. 2007. Disponível em: < http://www.valor.com.br >. Acesso em: 1 ago. 2007.

GORGATI, V. Os determinantes da estrutura de capital de empresas familiares brasileiras durante os processos sucessórios - contribuição da teoria da firma. Dissertação (Mestrado em Administração). Universidade de São Paulo, FEA/USP: 2000.

GOY, L. Bologna deixa Conselho, mas permanece presidindo a TAM. Valor, 20 dez. 2004. Disponível em: < http://www.valor.com.br >. Acesso em: 8 ago. 2007.

HERZOG, A. L. Em busca da identidade perdida. Portal Exame, 14 dez. 2006. Disponível em: 〈http://www.exame.com.br $>$. Acesso em: 20 nov. 2007.

KROEHN, M. O grande passo dos Grendene. Isto É Dinheiro, São Paulo 12 jul. 2007. Disponível em <http://www.terra.com.br/istoedinheiro $>$ Acesso em: 2 ago. 2007.

LAKATOS, E. M; MARCONI, M. A. Metodologia científica. São Paulo: Atlas, 1991.

LEONE, N. M. G. A sucessão não é tabu para os dirigentes da P.M.E. In: ENCONTRO NACIONAL DE PÓS GRADUAÇÃO EM ADMINISTRAÇÃO, 15, 1991, Salvador. Anais... Salvador: ANPAD, v. 7, p. 243-257, 1991.

LETHBRIDGE, T. A TAM voa alto sem Rolim. Portal Exame, 29 jul. 2005. Disponível em: <http://www.exame.com.br>. Acesso em: 6 out. 2007.

LETHBRIDGE, T. O desafio de sair do chão. Portal Exame, 30 jun. 2004. Disponível em: <http://www.exame.com.br>.Acesso em: 6 out. 2007.

LODI, J. B. A empresa familiar. São Paulo: Pioneira, 1978.

MACHADO, M. B. C.; SANTOS, M. S. Jotabê, agência de publicidade e promoções, que deu início à construção da marca Azaléia. In: CONGRESSO BRASILEIRO DE CIÊNCIAS DA COMUNICAÇÃ̃O, 30, 2007, Santos. Anais Eletrônicos... Santos: INTERCOM, 2007. CDROM.

MARTINEZ, C.; BALARIN, R. TAM coloca Bologna na presidência. Valor Econômico, São Paulo, 22 dez. 2003. Disponível em: < http://www.valor.com.br >. Acesso em: 1 ago. 2007.

MATURO, J. Indústria de calçados agora aposta em marcas próprias. Valor, 06 dez. 2004. Disponível em: < http://www.valor.com.br >. Acesso em: 1 ago. 2007.

MCCANN, J. E. Doce Sucesso. Rio de Janeiro: LTC, 1992.

MEYER, C. À procura de um presidente. Revista Exame, v. 42, n. 3, p. 22-30, 27 fev. 2008.

MINADEO, R. Classificação e Análise de Processos Sucessórios. In: SEMEAD, 11. São Paulo: FEA/USP. Anais Eletrônicos. São Paulo, 2008. CD-ROM. 
MINADEO, R.; RAPHAEL, D. A.; CUNHA, J. L. T. A Trajetória da TAM. XXII Encontro da Associação Portuguesa de História Econômica e Social. «Empresas e Instituições em Perspectiva Histórica». Universidade de Aveiro. Departamento de Economia, Gestão e Engenharia Industrial, maio 2003.

MORCK, R.; YEUNG, B. Family control and the rent-seeking society. Entrepreneurship Theory \& Practice, [s.1.], v. 28, n.4, 2004.

NAIDITCH, S. Depois que o dono se vai. Portal Exame, 25 maio 2004. Disponível em: <http://www.exame.com.br>. Acesso em: 1 ago. 2007.

NAKAMURA, P. Lucro da Azaléia cresceu 62,8\% no ano passado. Valor, 14 mar. 2007. Disponível em: < http://www.valor.com.br >. Acesso em: 1 ago. 2007.

NAKAMURA, P. Vulcabrás define planos para Azaléia. Valor, 17 jan. 2008.

NEUBAUER, F.; LANK, A. G. La empresa familiar: como dirigirla para que perdure. Bilbao: Deusto, 1999.

OLIVEIRA, D. P. R. Empresa Familiar: como fortalecer o empreendimento e otimizar o processo sucessório. São Paulo: Atlas, 1999. 256 p.

ONAGA, M. Marco Bologna volta para a TAM. Portal Exame, 2 mar. 2009.

RETRATO de família. HSM Management, v. 7, n. 6, p. 84-91, nov./dez. 2003.

RIBEIRO, M. S. A responsabilidade social como estratégia da atividade de relações públicas: caso Indústria de Calçados Azaléia. In: CONGRESSO BRASILEIRO DE CIÊNCIAS DA COMUNICAÇÃO, 26, 2003, Belo Horizonte. Anais Eletrônicos... Belo Horizonte: INTERCOM, 2008. CD-ROM.

ROCHA, R. E. V.; VIANA, F. L. E. Análise da competitividade da Indústria de Calçados da Região Nordeste. In: SIMPÓSIO DE ENGENHARIA DE PRODUÇÃO, 13, 2006, Bauru. Anais Eletrônicos... Bauru. UNESP, 2006. CD-ROM.

RODRIGUES, G. K. M.; CRAIDE, A.; TUDE, J. M. Interculturalidade: a chegada da Calçados Azaléia na Bahia e o encontro de duas culturas distintas. In: ENCONTRO NACIONAL DE PÓS GRADUAÇÃO EM ADMINISTRAÇÃO, 31, 2007. Rio de Janeiro: Anais Eletrônicos... Rio de Janeiro: ANPAD, 2007. CD-ROM.

SILVA JÚNIOR, A.; MUNIZ, R. M. Poder e sucessão: ascensão, declínio e falência de uma gestão familiar em uma empresa capixaba. Salvador: Organizações e Sociedade, v. 10, n. 26, p. 57-75, jan./abr. 2003.

STEIER L. P.; CHRISMAN, J. J.; CHUA, J. H. Entrepreneurial management and governance in family firms: an introduction. Entrepreneurship Theory and Practice, [s.1.], summer, 2004.

THÉRY, H. O transporte aéreo no Brasil: asas da centralidade. Mercator - Revista de Geografia da UFC, v. 2, n. 3, 2003. Disponível em: 
$<$ http://www.mercator.ufc.br/revista\%20mercator\%203\%20em\%20pdf/otranspaereonobrasil.p df>. Acesso em: 17 nov. 2007.

UBINHA, A. R.; PEDROSO, A.; CASSIANO, C. M. Marketing de Serviços e as estratégias utilizadas pelo Cmte. Rolim. In: Congresso Brasileiro de Ciências da Comunicação, 31, 2008, Natal. Anais Eletrônicos... Natal: INTERCOM, 2008. CD-ROM.

VARGA, L. Varig e TAM anunciam hoje união de suas operações. Folha, 06 fev. 2003. Disponível em: < http://www.valor.com.br >. Acesso em: 18 nov. 2007.

YIN, R. Método do caso. Porto Alegre: Bookman, 2001.

ZAHRA, S.; HAYTON, H.; SALVATO, C. Entrepreneurship in family vs. non-family firms: A resource-based analysis of the effect of organizational culture. Entrepreneurship Theory \& Practice, [s.1.], v. 28, n. 4, 2004. 